\title{
Buoyancy shutdown process for the development of the baroclinic jet structure of the Soya Warm Current during summer
}

\author{
Tatsuro Karaki $^{1} \mathbb{D} \cdot$ Humio Mitsudera ${ }^{2} \cdot$ Hiroshi Kuroda $^{3}$
}

Received: 29 August 2017 / Revised: 20 January 2018 / Accepted: 26 January 2018 / Published online: 12 February 2018

(c) The Author(s) 2018. This article is an open access publication

\begin{abstract}
The Soya Warm Current (SWC), which is the coastal current along the northeastern part of Hokkaido, Japan, has a notable baroclinic jet structure during summer. This study addresses the formation mechanism of the baroclinic jet by analyzing a realistic numerical model and conducting its sensitivity experiment. The key process is the interaction between the seasonal thermocline and the bottom Ekman layer on the slope off the northeastern coast of Hokkaido; the bottom Ekman transport causes subduction of the warm seasonal thermocline water below the cold lower-layer water, so the bottom mixed layer develops with a remarkable cross-isobath density gradient. Consequently, the buoyancy transport vanishes as a result of the thermal wind balance in the mixed layer. The SWC area is divided into two regions during summer: upstream, the adjustment toward the buoyancy shutdown is in progress; downstream, the buoyancy shutdown occurs. The buoyancy shutdown theory assesses the bottom-mixed-layer thickness to be $50 \mathrm{~m}$, consistent with observations and our numerical results. The seasonal thermocline from June to September is strong enough to establish the dominance of the buoyancy shutdown process over the frictional spindown.
\end{abstract}

Keywords Soya Warm Current · Baroclinic jet · Buoyancy shutdown · Frictional spindown $\cdot$ Seasonal thermocline $\cdot$ Bottom Ekman transport $\cdot$ Realistic numerical model

\section{Introduction}

The Soya Warm Current (SWC) is the coastal current flowing southeastward along the northeastern part of Hokkaido, Japan (Fig. 1a). The SWC has a surface-intensified baroclinic jet structure during summer (Matsuyama et al. 2006; Ishizu et al. 2006; Fukamachi et al. 2008). As shown by previous observations (e.g., Matsuyama et al. 2006; see also Fig. 2), the strong horizontal density gradient of approximately $25-26 \sigma_{\theta}$, which is located $10-20 \mathrm{~km}$ offshore from

Tatsuro Karaki

karakita@lowtem.hokudai.ac.jp

1 Graduate School of Environmental Science, Hokkaido University, Nishi-5, Kita-10, Kita-ku, Sapporo, Hokkaido 060-0810, Japan

2 Institute of Low Temperature Science, Hokkaido University, Nishi-8, Kita-19, Kita-ku, Sapporo, Hokkaido 060-0819, Japan

3 Hokkaido National Fisheries Research Institute, Fisheries Research and Education Agency, 116 Katsurakoi, Kushiro, Hokkaido 085-0802, Japan the coast, causes a baroclinic jet with a velocity exceeding $1 \mathrm{~m} \mathrm{~s}^{-1}$ near the surface (Fukamachi et al. 2008). Since the SWC region is a commercial fishing ground in Japan (e.g., Shimada et al. 2012), its hydrographic conditions have stimulated much interest in terms of not only oceanography but also in relation to the fisheries and seafood industries.

In this article, we will discuss a formation mechanism of the baroclinic jet structure of the SWC during summer. We hypothesize that the seasonal thermocline in the Soya/ La Pérouse Strait (referred to as the Soya Strait hereafter) plays an important role in the formation of the baroclinicity of the SWC. The warm and salty SWC $\left(T>7{ }^{\circ} \mathrm{C}\right.$, $S>33.6$ ), originating in the Japan Sea, flows in contact with the cold and fresh water in the Sea of Okhotsk $\left(T<2{ }^{\circ} \mathrm{C}\right.$, $32.8<S<33.4)$ along the Hokkaido coast. As shown in Fig. 2, however, the salinity front between 33.2 and 33.8 psu, which is a boundary between the SWC water and the Okhotsk Sea water, hardly contributes to the density gradient because of density compensation due to temperature. Rather, the temperature front of $10-15{ }^{\circ} \mathrm{C}$ inside the SWC is responsible for the density front of $25-26 \sigma_{\theta}$ where isotherms incline steeply. Since the summer SWC water on the 


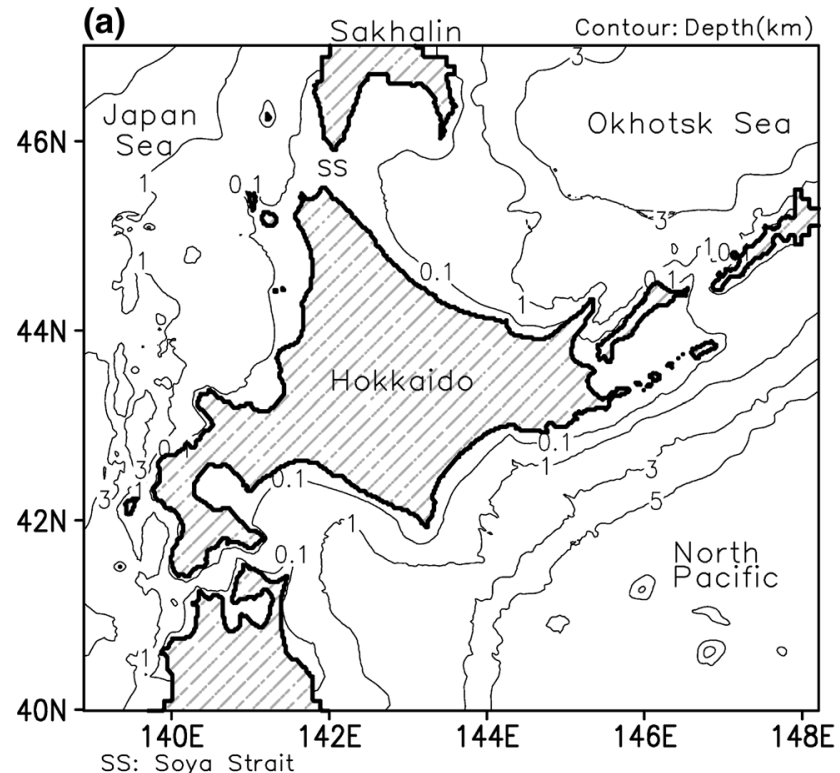

Fig. 1 a Bathymetry and domain of the Hokkaido model. The model domain around the Okhotsk Sea is enlarged in the $\mathbf{b}$ oceanic bathymetry near the northeastern Hokkaido coast. Regarding a sensitivity

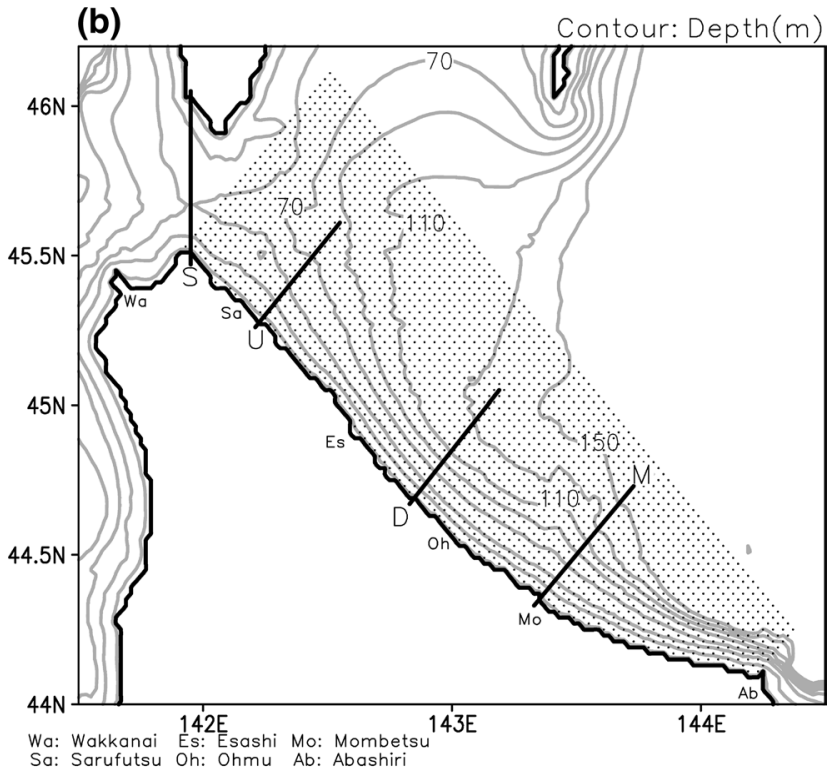

experiment, bottom friction is neglected at grid points denoted by dots. Line S, U, D and M represent the locations of four vertical sections

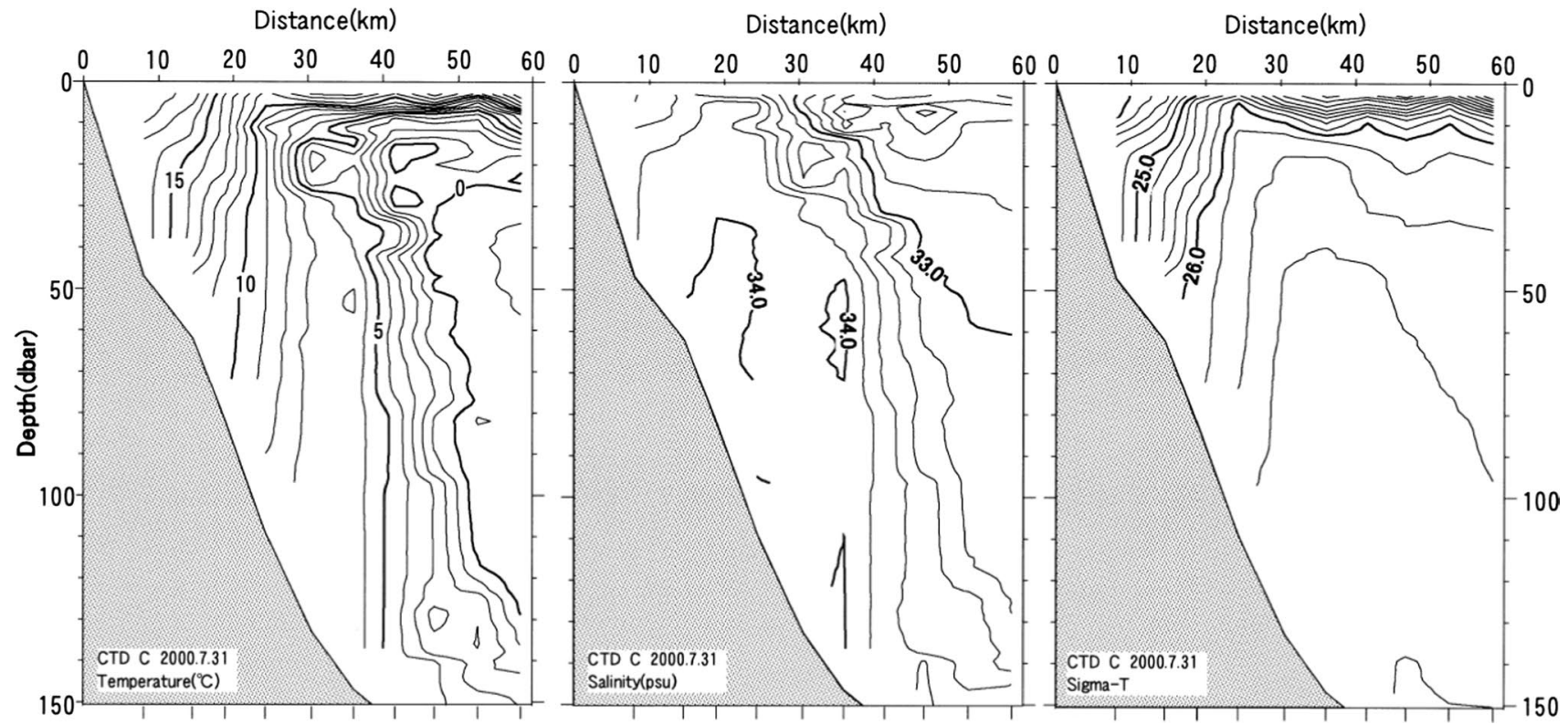

Fig. 2 Vertical sections of temperature (left), salinity (center) and density (right) observed on 30 July 2000 by Matsuyama et al. (2006). The horizontal position of the vertical sections roughly corresponds to that of line M (Fig. 1b)

Hokkaido side of the Soya Strait (Fig. 3) is highly stratified because of the seasonal thermocline (Aota et al. 1988; Nakata et al. 1999; Nakanowatari et al. 2017), we consider that the seasonal thermocline in the strait tilts as the summer SWC flows downstream, so that a baroclinic jet structure with a marked horizontal temperature gradient develops along the Hokkaido coast (Matsuyama et al. 2006; Ishizu et al. 2006). In other words, the SWC changes its structure from a barotropic current, driven by the sea level difference between the Japan Sea and the Sea of Okhotsk at the Soya Strait and the geostrophic adjustment (Ohshima 1994), into a baroclinic current in the downstream region from the strait. This is different from other outflows from straits, such as the Tsugaru Warm Current (e.g., Kubokawa 1991) and the 


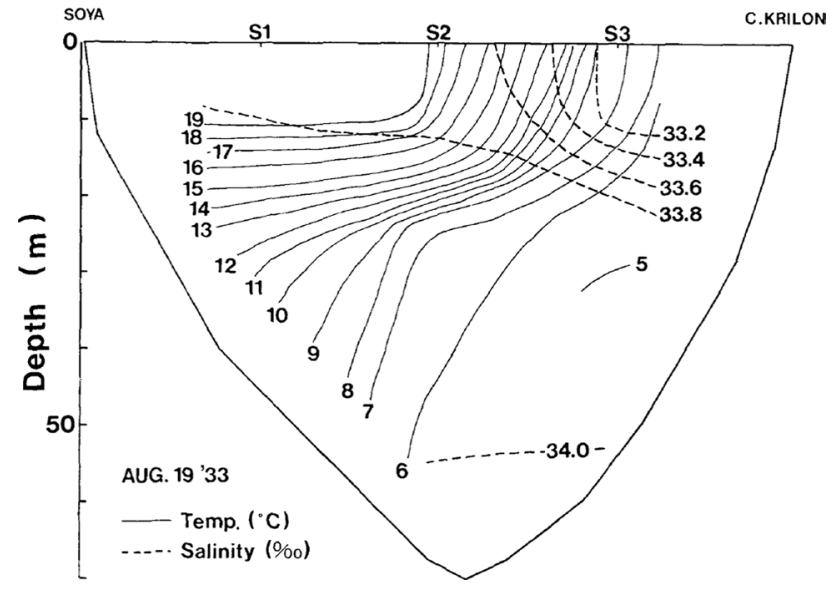

Fig. 3 Vertical section of temperature (solid line) and salinity (dashed line) in the Soya Strait observed on 19 August 1933, from Aota et al. (1988)

Okhotsk water outflow from the Bussol Strait (e.g., Yasuda et al. 2000), because these are characterized by outflows of relatively light, low-potential-vorticity waters.

Concerning dynamics of the SWC, Mitsudera et al. (2011) showed that a barotropic current with a subsurface thermocline obtains a baroclinic jet structure as it passes over a shallow sill in a strait as a result of hydraulic control associated with internal Kelvin waves. The theory implies that the seasonal thermocline inclines towards the sea surface so steeply that the cold water below the thermocline outcrops near Cape Krilon in Sakhalin Island (e.g., Fig. 3). In their idealized model, further, since the upwelling over the shallow sill induces long baroclinic Rossby waves along the current downstream, a cold water belt develops subsequently as a result of adjustment through a frontal wave propagation (namely, a baroclinic adjustment). This is consistent with observational results such that the outcrop of cold water is frequently seen offshore of the summer SWC (e.g., Ishizu et al. 2006).

Mitsudera et al. (2011) conjectured that the baroclinic adjustment on a barotropic current downstream of the strait causes both the cold water belt and the formation of the baroclinic jet structure of the current. However, on a closer examination of their idealized numerical results, a baroclinic structure in the current was established first, and the cold water belt developed afterwards through the frontal wave propagation. Therefore, the formation of the baroclinic jet structure in the SWC should be discussed separately from the cold belt formation. In particular, effects of the bottom friction were overlooked in their theoretical argument.

In this article the formation of the baroclinic jet structure in the SWC is studied from the viewpoint of the buoyancy shutdown theory (e.g., Garrett et al. 1993; Chapman and Lentz 1997; Chapman 2002). The theory focuses on

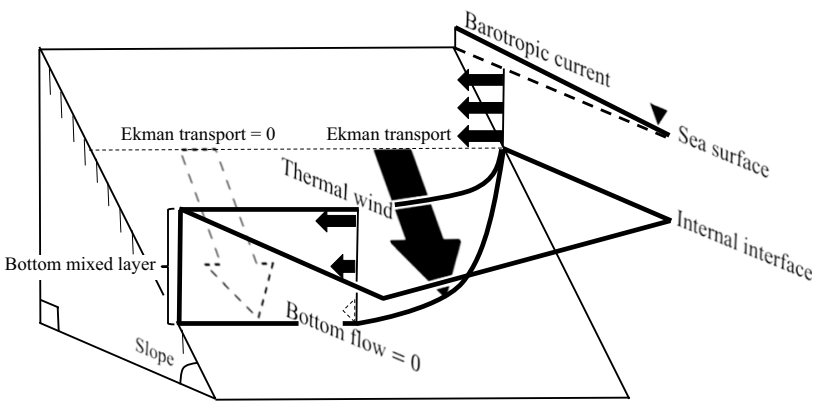

Fig. 4 A schematic representation of the buoyancy shutdown process

the interaction between the stratification and the bottom Ekman layer and explains the adjustment process of a stratified along-isobath flow over a sloping bottom. The steady state has been referred to as the buoyancy shutdown (e.g., Benthuysen et al. 2015) or the buoyancy arrest (e.g., Brink and Lents 2010). This study uses the former. Note that we do not discuss the formation of the cold water belt but focus on the baroclinic jet formation associated with the buoyancy shutdown.

According to both Chapman and Lentz (1997) and Chapman (2002), the buoyancy shutdown process may be described schematically as in Fig. 4. Suppose an initial state given as a barotropic along-isobath current with horizontal isopycnal surfaces, flowing on the right-hand side of the shallower part of a uniform slope. The bottom Ekman transport then occurs in the downslope direction, so that a lighter water subducts under a denser water via the bottom Ekman layer. This induces vertical mixing above the Ekman layer. As a result, the initial horizontally uniform density structure turns into a vertically uniform structure, forming the bottom mixed layer with a horizontal density gradient. The bottom Ekman transport (the buoyancy transport) pushes the mixed layer offshore until it thickens enough to cease its alongisobath bottom flow because of the thermal wind balance. The bottom Ekman transport then vanishes (namely, the buoyancy shutdown). As the current no longer suffers from frictional dissipation, the current achieves a steady state with a bottom mixed layer and vertically sheared velocity structures.

We hypothesized that the buoyancy shutdown theory is a reasonable application to the summer SWC. Since the SWC is a geostrophic current flowing on the right-hand side of the northeastern coast of Hokkaido (Ohshima 1994), the bottom Ekman transport likely occurs in the downslope direction and can tilt the seasonal thermocline in the same way as the theory. The slope along the northeastern coast of Hokkaido is nearly uniform (Fig. 1b), which is also suited for the theory. According to Matsuyama et al. (2006) and Ebuchi et al. (2009), in addition, the temperature-front structure and the maximum speed of the summer SWC do not vary 
significantly in the downstream region. This suggests that the dissipation due to the bottom friction acting on the SWC is weak, consistent with the theory.

The goal of this study is to clarify the formation mechanism of the baroclinic jet structure of the summer SWC. We analyze a realistic numerical model (Kuroda et al. 2014) and conduct its sensitivity experiment. This article is organized as follows. The outline of the model and its reproducibility of the SWC are shown in Sect. 2. The buoyancy shutdown process of the SWC is investigated in Sect. 3. In Sect. 4, the sensitivity of the SWC to the bottom friction and the seasonal thermocline is examined. Section 5 presents the summary and discussion of this study.

\section{Model overview}

\subsection{Model configuration}

We used a realistic numerical ocean model (referred to as the Hokkaido model hereafter) constructed by Kuroda et al. (2014). The Hokkaido model is a triply nested model based on the Regional Ocean Modeling System (ROMS) (e.g., Shchepetkin and McWilliams 2005). Three models with resolutions of $1 / 2^{\circ}, 1 / 10^{\circ}$ and $1 / 50^{\circ}$ are connected by one-way nesting. The realistic topography (Fig. 1a) is incorporated into the Hokkaido model. The horizontal resolution of $1 / 50^{\circ}$ is approximately $2 \mathrm{~km}$. As shown by Sakamoto et al. (2010), grid sizes less than at least $2 \mathrm{~km}$ are essential to simulate the buoyancy shutdown process sufficiently. The Hokkaido model employs a terrain-following $S$ coordinate with 21 vertical layers. The vertical resolutions around the SWC region (depth $<100 \mathrm{~m}$ ) are within $5 \mathrm{~m}$, which is a typical scale for the Ekman-layer thickness. Therefore, we expect that the Hokkaido model can represent a bottom flow field of the SWC. The bottom stress is modeled by the quadratic drag law with a coefficient of 0.003 . Instead of K-profile parameterization (KPP) in the original model configuration (Kuroda et al. 2014), the Mellor-Yamada level 2.5 scheme (Allen et al. 1995) is used to examine the mixing process adjacent to the bottom. The Hokkaido model is driven by climatologic fluxes. At the sea surface, we sequentially estimate momentum, heat and freshwater fluxes using CORE normalyear forcing (Large and Yeager 2004) during the model run. On the lateral boundaries, the 3.8-day mean output derived from the $1 / 10^{\circ}$ parent model (Kuroda et al. 2013) is imposed. The parent model also provides the initial condition with the Hokkaido model. The total integrated period of the three models is 20 years. The Hokkaido model is integrated only for the last 5 years. We analyzed the monthly mean outputs in the last year of the integration. Although the Hokkaido model does not contain the sea ice, this would not be a serious problem for reproducing the summer SWC. Further, we do not consider tides as we focus on the basic mechanism of the buoyancy shutdown processes that cause baroclinicity in the SWC. However, tides potentially affect the buoyancy shutdown process, since the tidal forcing enhances the bottom drag dissipation (e.g., Lee et al. 2000).

\subsection{Reproducibility of the SWC}

In this subsection we present simulated features of the summer SWC in the Hokkaido model to evaluate both the reproducibility and the hypothesis mentioned in Sect. 1, especially from a point of view of the relations between the SWC and the seasonal thermocline.

Figure 5a shows the simulated monthly mean sea surface height ( $\mathrm{SSH}$ ) in August. A large across-shelf SSH gradient is seen off the coast of the southwestern Sakhalin. It extends to the northeastern coast of Hokkaido through the Soya Strait, representing the SWC. This is a consequence of the geostrophic adjustment processes shown by Ohshima (1994); the sea level difference between the Sea of Okhotsk and the Japan Sea across the Soya Strait propagates as shelf waves along the Hokkaido and Sakhalin coasts. Therefore, the adjustment process across the Soya Strait is essentially barotropic.

Corresponding to the SSH distribution in Fig. 5a, the model reproduced a southeastward jet with a speed of $0.6-0.8 \mathrm{~m} \mathrm{~s}^{-1}$ from the southwestern coast of the Sakhalin up to the eastern end of the northeastern coast of Hokkaido (Fig. 5b). This jet speed is scaled by the geostrophic balance. The simulated jet axis is located $10-20 \mathrm{~km}$ from the coast in a similar manner to the observations, although the reproduced speed is slower than the result observed by ocean radars, which is greater than $1 \mathrm{~m} \mathrm{~s}^{-1}$ (Ebuchi et al. 2009). The simulated SST off the northeastern coast of Hokkaido ranges between 18 and $20{ }^{\circ} \mathrm{C}$, which is similar to the SST observed by satellite (e.g., Ishizu et al. 2006). The SST is colder around the southwestern tips of the Sakhalin than its surroundings as observed. This implies that the hydraulic control, shown theoretically by Mitsudera et al. (2011), occurs in the model, and the relatively cold water is apparent offshore of the SWC in the monthly mean field.

Figure 6 shows a vertical section for the simulated monthly mean temperature and salinity along the Soya Strait in August. As in the observations (Fig. 3), the simulated SWC water is characterized by highly stratified water because of the seasonal thermocline close to the Hokkaido coast rather than by a thick (or low-potential-vorticity) outflow water. However, the seasonal thermocline tilts towards the downward slope substantially in the downstream region away from the Soya Strait (Fig. 7a), as observed (see Fig. 2). The simulated temperature front of $9-18{ }^{\circ} \mathrm{C}$ exists between the coast and the salinity front of $33-34$ psu (the outer bound of the SWC). Thus, it is the temperature front that 
(a)

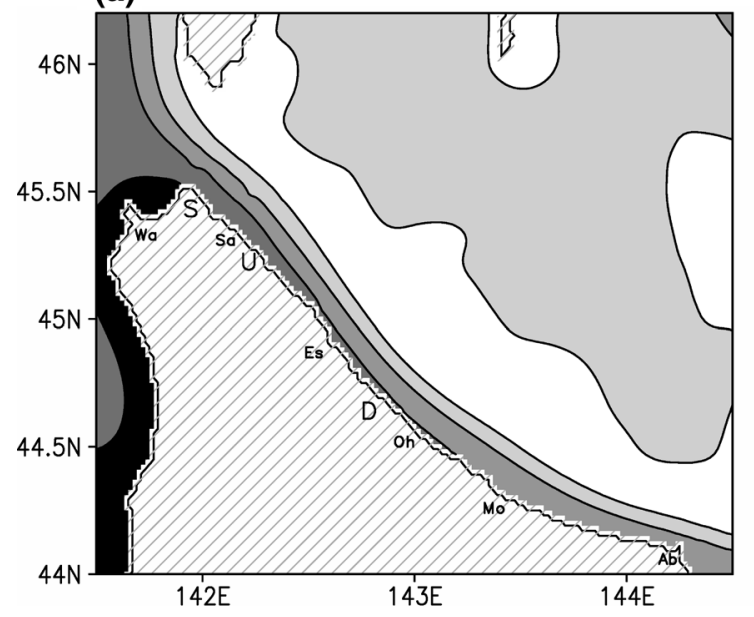

(b)

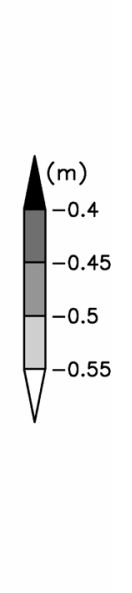

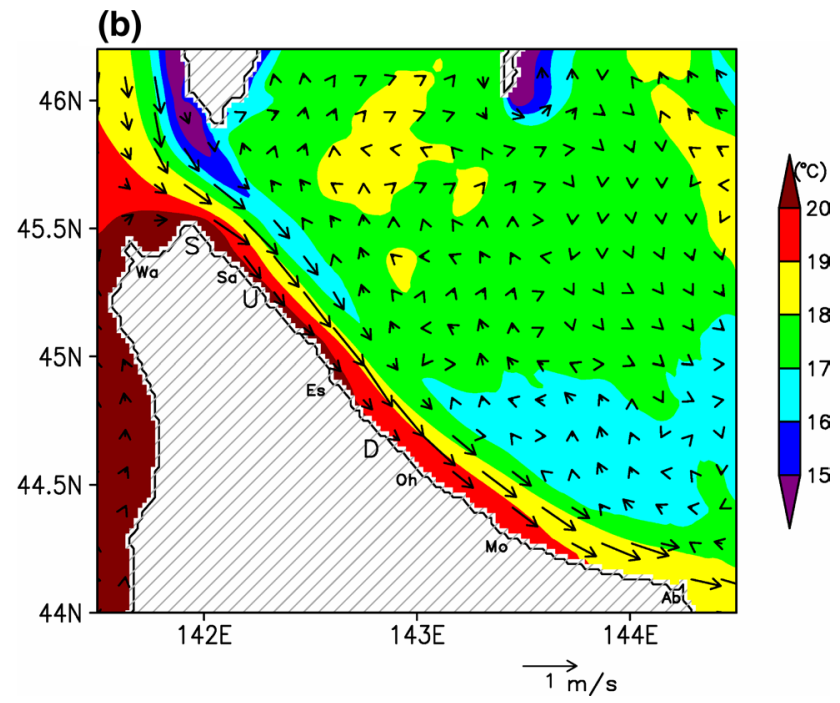

Fig. 5 Maps of the monthly mean of simulated a sea surface height (SSH), b current velocity (arrows) and temperature (color shades) at the sea surface in August

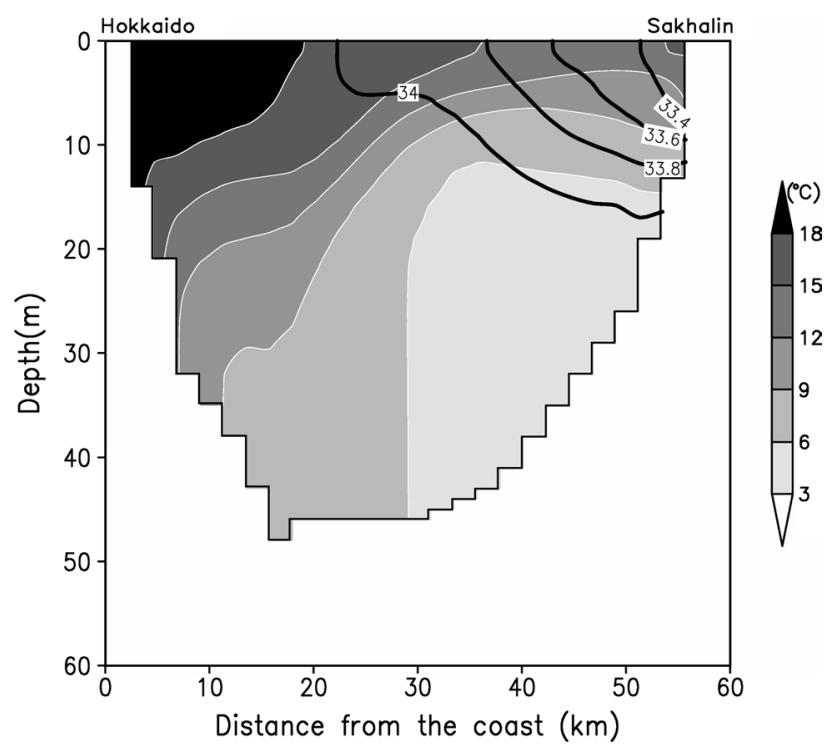

Fig. 6 Vertical section of the monthly mean of simulated temperature (shades with white contours) and salinity (thick black contours) fields along line S (Fig. 1b) in August. The contour interval is $0.2 \mathrm{psu}$

corresponds to the density front associated with the baroclinic jet of the SWC, whose maximum speed is approximately $0.7 \mathrm{~m} \mathrm{~s}^{-1}$ in the model (Fig. 7b). Alternatively, the boundary between the SWC and the Okhotsk water is not a direct cause of the baroclinic jet of the summer SWC. This is consistent with observations (Fig. 2).

Next, we present the seasonal variations of the SWC in the Hokkaido model. Figure 8a shows the simulated monthly mean volume transport through the Soya Strait together with the observational results (Fukamachi et al. 2010). The
Hokkaido model reproduces the annual cycle of the SWC transport, such as the maximum (minimum) transport in summer (winter), although the model tends to underestimate the SWC transport in almost all months. Seasonal variations of the simulated temperature and vertical profile of alongisobath velocity around the SWC's jet axis (Fig. 8b) also correspond well with observational results (e.g., Aota 1975; Fukamachi et al. 2008); the strong vertical shear emerges in the SWC when the seasonal pycnocline appears, especially when the peak is from July to September.

To sum up, the Hokkaido model reproduces the observed features well, especially the relations between the SWC and the seasonal thermocline, although the simulated speed and volume transport tend to be slightly weaker than those observed. Thus, the analysis using the Hokkaido model is appropriate for studying the formation mechanism of the baroclinic jet.

\section{Buoyancy shutdown process of the SWC}

We investigated the cross-isobath bottom flow to detect the buoyancy shutdown process in the summer SWC (Fig. 9). The cross-isobath bottom flow was obtained by taking an inner product between the gradient of bathymetry and the horizontal velocity in the bottom layer of the model (Sakamoto et al. 2010).

Figure 9 shows that the cross-isobath bottom flow is almost zero in the coastal area shallower than $80 \mathrm{~m}$ between approximately $142.5^{\circ} \mathrm{E}$ and $144.0^{\circ} \mathrm{E}$ where the SWC flows. In this region, the isopycnals on the bottom (black contours in Fig. 9) are parallel to the water depth contours (white 

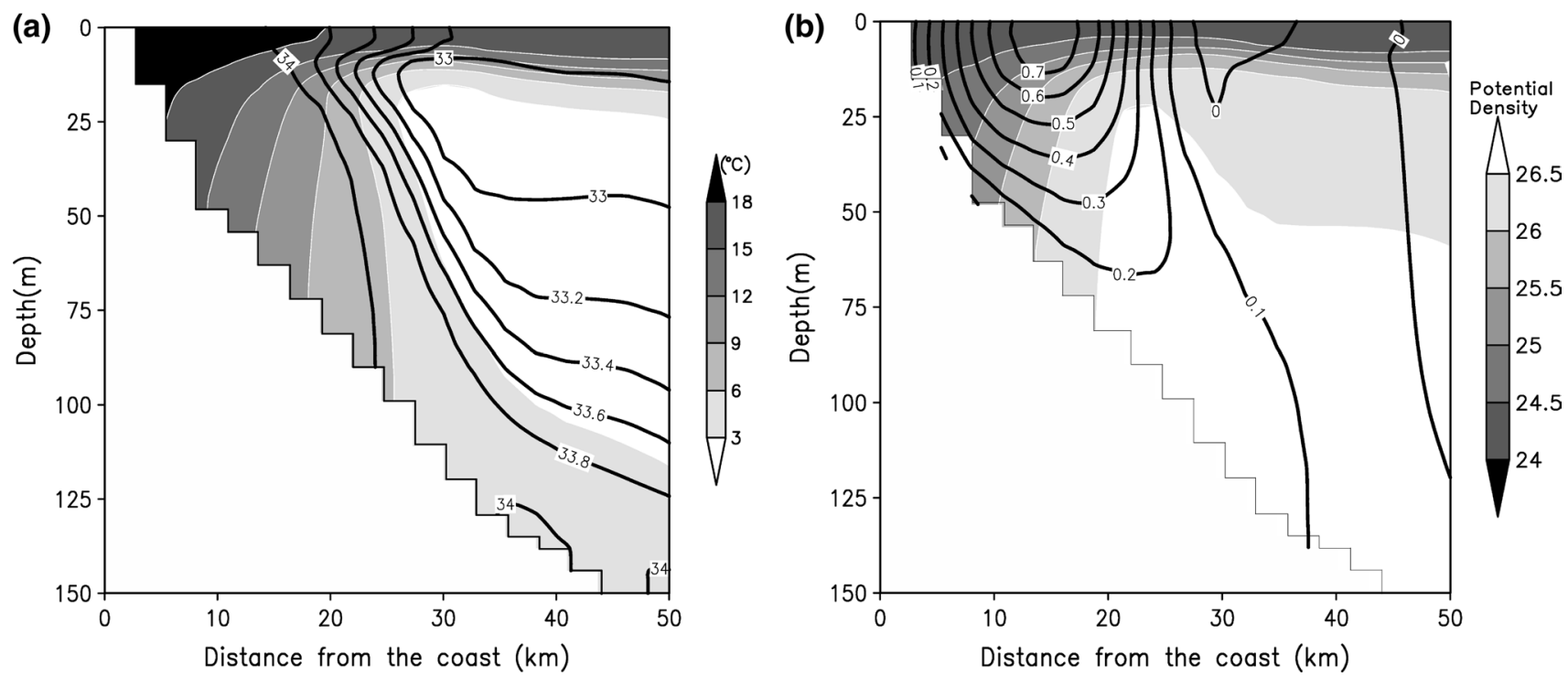

Fig. 7 Vertical sections of the monthly mean of simulated a temperature, salinity - the same as Fig. 6, but for line M (Fig. 1b), b along-isobath velocity (thick black contours) and density (white contours with gray shades) fields along line $\mathrm{M}$ (Fig. $1 \mathrm{~b}$ ). The contour interval is $0.1 \mathrm{~m} \mathrm{~s}^{-1}$ in $\mathbf{b}$

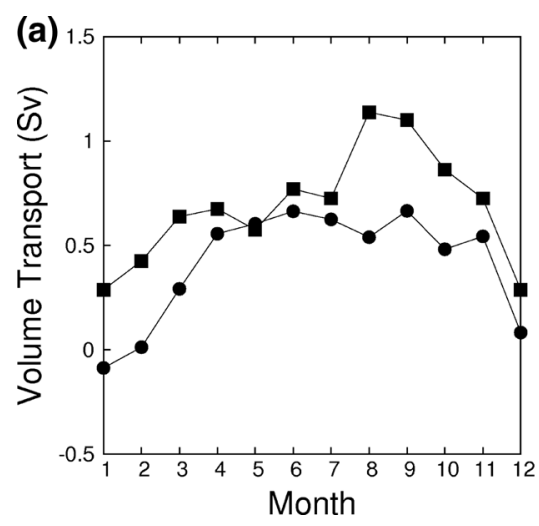

Fig. 8 a Annual variation of monthly volume transport through the Soya Strait. The simulated volume transport (black line with closed circles) is estimated on line S (Fig. 1b), and the observed value (black line with closed squares) is based on Fukamachi et al. (2010).

contours). This indicates that the baroclinic jet is arrested on isobaths eastward of $142.5^{\circ} \mathrm{E}$ away from the Soya Strait. Thus, the buoyancy shutdown occurs in the downstream region of the SWC where the baroclinic jet exits. On the other hand, the cross-isobath bottom flow between the Soya Strait and $142.5^{\circ} \mathrm{E}$ is not zero, being accompanied by the offshore movement of the density contours. Therefore, the adjustment toward the buoyancy shutdown occurs immediately downstream from the Soya Strait.

We analyzed the vertical mixing along an isopycnal contour in Fig. 9 to investigate the development of the bottom mixed layer as the SWC flows downstream. Figure 10 exhibits the vertical section of the monthly mean turbulent kinetic energy along the isopycnal of $26.0 \sigma_{\theta}$. The contours b Space-time diagram of monthly mean of temperature (shades) and along-isobath velocity (black contours) at a fixed position with a water depth of $70 \mathrm{~m}$ on line M (Fig. 1b)

in Fig. 10 represent the upper bound of the bottom mixed layer evaluated by three criteria based on a density difference from the bottom value $\left(26.0 \sigma_{\theta}\right)$. If $\Delta \sigma_{\theta}=0.5$ is used for the criterion by considering observed (Fig. 2) and numerical (Fig. 7b) density profiles, we can assess the vertical scale of the SWC's mixed layer as $50 \mathrm{~m}$.

Figure 10 shows that the bottom mixed layer thickens gradually from less than $20 \mathrm{~m}$ at the Soya Strait to approximately $50 \mathrm{~m}$ at approximately $142.5^{\circ} \mathrm{E}$ as the water mass of $26.0 \sigma_{\theta}$ migrates offshore from the water depth of $30 \mathrm{~m}$ to $60 \mathrm{~m}$. The mixed-layer development ceases farther downstream as vertical mixing weakens by one order of magnitude. The evolution of the bottom mixed layer corresponds to the spatial variation in the cross-isobath bottom flow (see 
Fig. 9 Monthly mean of the simulated cross-isobath velocity (color shades) and density (black contours) field in the deepest/21st layer of the model during August. The contour interval of density is $1 \sigma_{\theta}$. The dotted line indicates the isopycnal line of $25.5 \sigma_{\theta}$. White contours also represent the water depths of 40,60 and $80 \mathrm{~m}$
Fig. 10 Vertical section of monthly mean of the simulated turbulent kinetic energy field (color shades) during August along the isopycnal line of $26.0 \sigma_{\theta}$ in Fig. 9. The turbulent kinetic energy is illustrated by a logarithmic scale. The contour lines indicate the bottom-mixedlayer thicknesses, each of whose criteria $\left(\Delta \sigma_{\theta}=0.1,0.5\right.$ and 1.0 , respectively) is different in density from the sea bottom

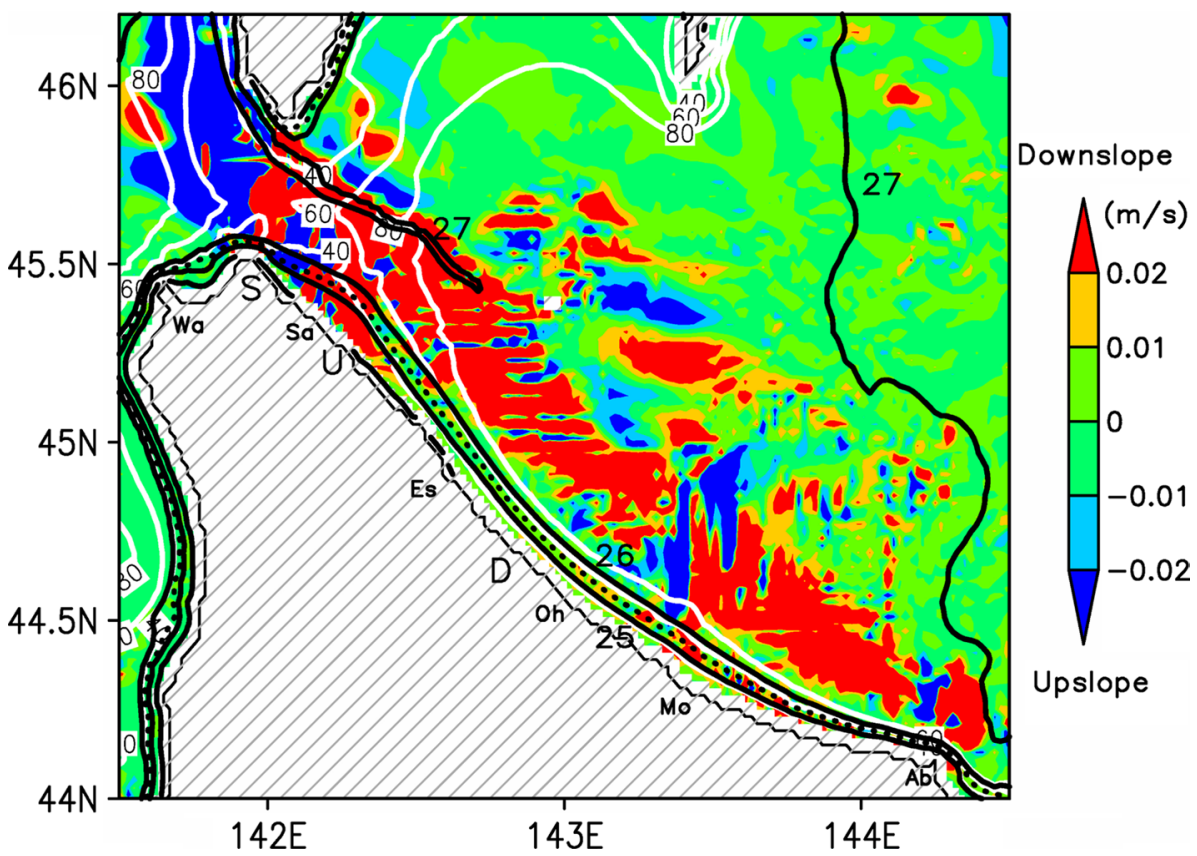

Turbulent

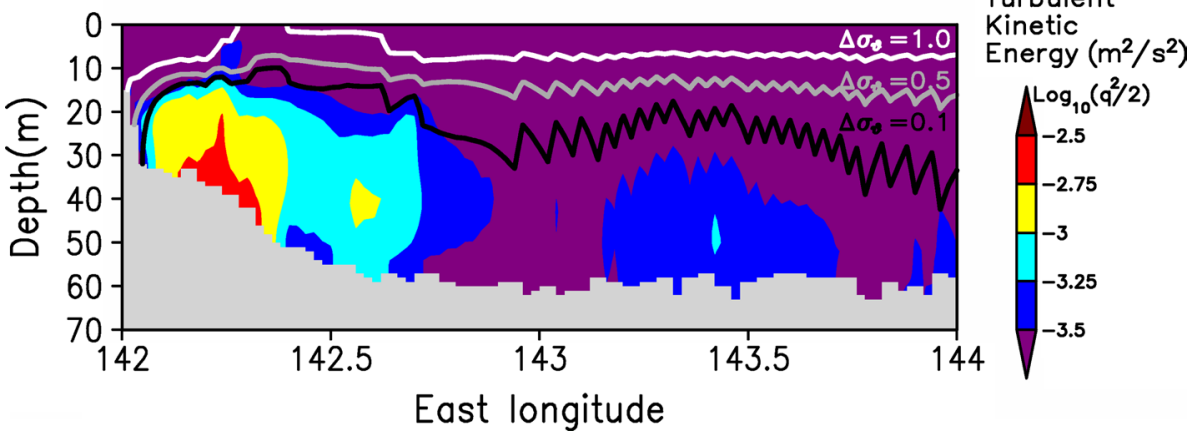

(a)

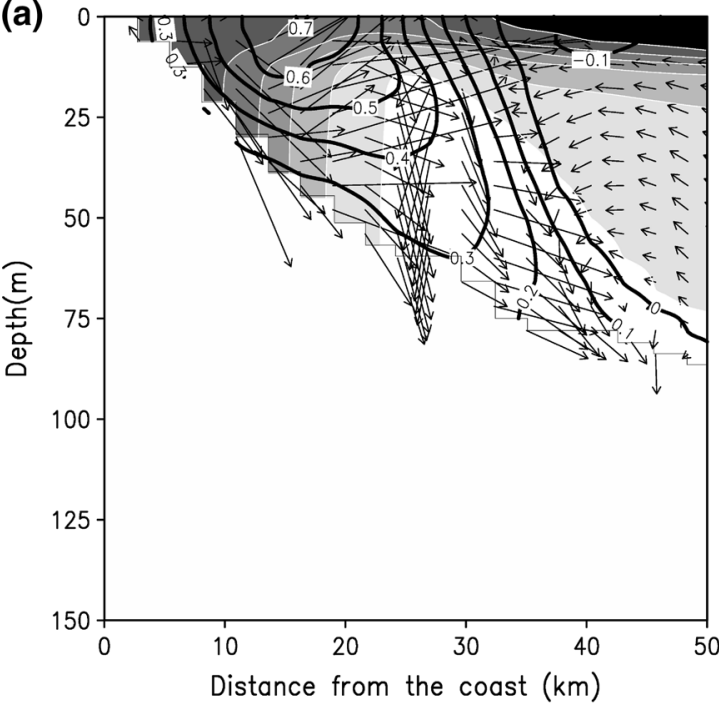

(b)

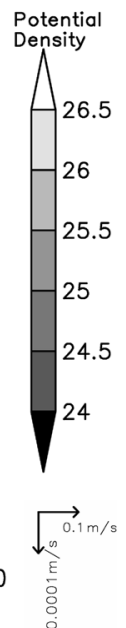

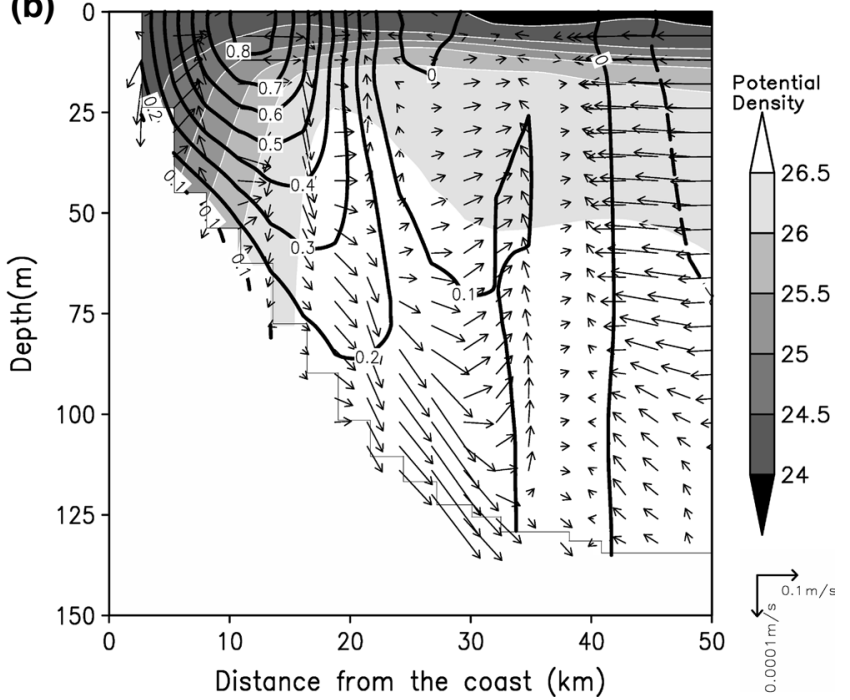

Fig. 11 The same as Fig. 7b, but for a line $U$ and $\mathbf{b}$ line D, superimposing the cross-sectional circulations (arrows) 
Fig. 9). That is, it is in the upstream region of the SWC where the bottom Ekman transport causes subduction of the warm seasonal thermocline water below the cold lower-layer water, resulting in the growth of the bottom mixed layer. Subsequently, the bottom mixed layer obtains a uniform thickness of approximately $50 \mathrm{~m}$ between approximately $142.5^{\circ} \mathrm{E}$ and $144.0^{\circ} \mathrm{E}$. Therefore, there is a clear separation between the up- and downstream regions of the SWC, where in the former the adjustment toward the buoyancy shutdown is in progress, while in the latter the buoyancy shutdown occurs.

The differences between the up- and downstream regions of the summer SWC are also obvious from cross-sectional circulations where the baroclinic jet structure forms within approximately $20 \mathrm{~km}$ from the coast (Fig. 11). In the upstream section (Fig. 11a), the offshore cross-isobath velocity $\left(>0.1 \mathrm{~m} \mathrm{~s}^{-1}\right)$ exits in the SWC's flow section with a bottom-mixed-layer thickness of approximately $30 \mathrm{~m}$. In the downstream section (Fig. 11b), however, the offshore crossisobath velocity nearly vanishes up to a depth of approximately $90 \mathrm{~m}$ where the bottom mixed layer exists (i.e., the buoyancy shutdown occurs).

According to Trowbridge and Lentz (1991), a vertical scale that is necessary for the buoyancy shutdown can be written as:

$\bar{\delta} \approx f \bar{u}_{\mathrm{T}}\left(N^{2} \alpha\right)^{-1}$,

where $\delta$ is the thickness of the bottom mixed layer in the buoyancy shutdown; $f$ is the Coriolis parameter; $u_{\mathrm{T}}$ is the along-isobath velocity above the top of the boundary layer; $N$ is the buoyancy frequency; $\alpha$ is the bottom slope. Overlines mean that each variable is temporally averaged. In Eq. (1), it is assumed that $g \rho_{0}^{-1} \Delta \bar{\rho} / \Delta y \approx N^{2} \alpha$; here $g$ is gravitational acceleration; $\rho_{0}$ is the standard density; $\Delta \rho / \Delta y$ is the density gradient across the boundary layer. In the SWC case, the scale of each parameter in Eq. (1) is estimated as $\rho_{0}=1000 \mathrm{~kg} \mathrm{~m}^{-3}, g=10 \mathrm{~m} \mathrm{~s}^{-2}$, and $f=0.0001 \mathrm{~s}^{-1}, \alpha=0.005$, whereas Figs. 7b and $11 \mathrm{~b}$ indicate that $u_{\mathrm{T}}=1 \mathrm{~m} \mathrm{~s}^{-1}$ and $\Delta \rho / \Delta y=0.0002 \mathrm{~kg} \mathrm{~m}^{-4}$, so that $N=0.02 \mathrm{~s}^{-1}$. Thus, Eq. (1) evaluates the SWC vertical scale to obtain the buoyancy shutdown as $50 \mathrm{~m}$, consistent with the observed (Fig. 2) and numerical (Figs. 7b, 10, 11b) bottom-boundary-layer thicknesses.

To conclude, the baroclinic jet structure of the SWC is well explained by the buoyancy shutdown theory. The adjustment process of the SWC is also seen in a similar way in July and September (not shown), when the subsurface pycnocline and the surface-intensified vertical shear are enhanced in the Hokkaido model (Fig. 8b).

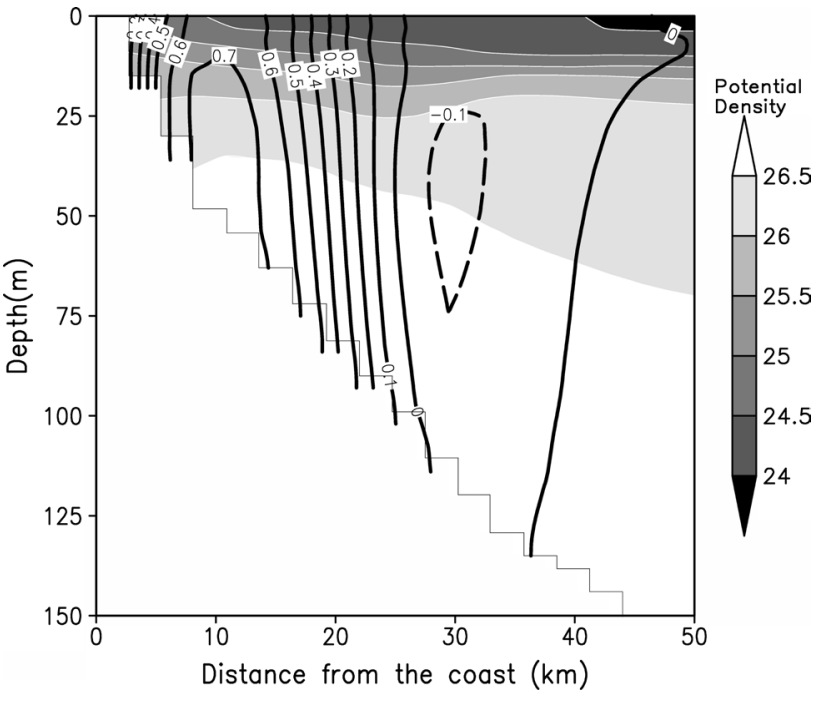

Fig. 12 Same as Fig. 7b, but for zero bottom friction over the coastal slope (see Fig. 1b). Negative velocity opposite the direction of the SWC is emphasized by dashed contour lines

\section{Sensitivity of the SWC}

In this section, the importance of the buoyancy shutdown process on the SWC's current structure is examined by the two kinds of methods as follows: a sensitivity experiment to the bottom friction; a comparison between the SWC in April and that in August by focusing on the presence or absence of the seasonal thermocline.

\subsection{Bottom friction}

We examined the sensitivity of the baroclinic jet structure to the bottom friction on the northeastern Hokkaido coastal slope. We turned off the bottom stress at the dotted region in Fig. 1b and ran this "no-bottom-stress" model over the same period (referred to as the sensitivity experiment) as that using the previously described Hokkaido model (referred to as the control run in this section). The most important point of the sensitivity experiment is that the interaction between the seasonal thermocline and the bottom Ekman layer on the northeastern coastal slope of Hokkaido does not occur because of the absence of bottom friction. That is, the buoyancy shutdown does not occur.

Figure 12 displays the vertical section of the density and the along-isobath velocity fields on line M (Fig. 1b) in the sensitivity experiment. Without the buoyancy shutdown process, the sharp density front that creates the surface-intensified baroclinic jet is no longer established. Instead, the seasonal thermocline remains, so that the along-isobath velocity in Fig. 12 is almost vertically uniform. Thus, we conclude that bottom friction, or the 


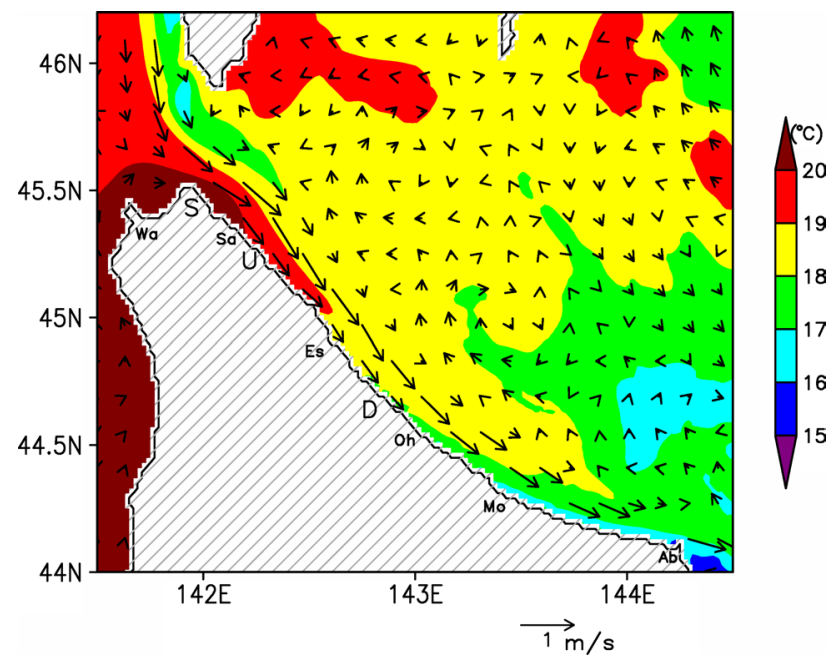

Fig. 13 The same as Fig. 5b, but for zero bottom friction over the coastal slope (see Fig. 1b)

buoyancy shutdown process, is essential to create the surface-intensified baroclinic jet structure as in the control experiment (Fig. 7b).

On closer examination, we noticed that the SWC in the sensitivity experiment exhibits a bottom-intensified velocity structure $\left(>0.7 \mathrm{~m} \mathrm{~s}^{-1}\right)$ approximately $10 \mathrm{~km}$ offshore from the coast. This may be a consequence of the geostrophic adjustment by shelf waves in a stratified fluid (Rhines 1970; Pedlosky 1987). The adjustment is consistent with Ohshima (1994), although in the presence of the stratification, the vortex stretching by the bottom slope occurs effectively near the bottom.

The sensitivity experiment can also evaluate how much the baroclinic adjustment influences the development of the baroclinic jet structure of the SWC in reality (Mitsudera et al. 2011). A cold water upwelling occurs around the southwestern Sakhalin tips (Fig. 13), consistent with the hydraulic control theory. As shown in Fig. 13, however, the formation of the cold water belt is not reproduced further downstream in the sensitivity experiment where the SWC current structure is approximately barotropic (Fig. 12). This implies that the barotropic SWC is not suitable for a propagation of a surface frontal wave (i.e., the baroclinic adjustment). Considering that the control case represents the cold water belt realistically (Fig. 5b), the baroclinic jet structure caused by the bottom Ekman transport is essential for the baroclinic adjustment, thereby producing the full development of the baroclinic jet including the cold water belt.

\subsection{Seasonal thermocline}

We compared the monthly mean of April with that of August in the Hokkaido model to examine the sensitivity of the SWC current structure to the seasonal thermocline. Since the simulated inflow conditions at the Soya Strait-i.e., the volume transport (Fig. 8a) and the surface speed (Figs. 5b, 14a) - are comparative between April and August, the presence or absence of the seasonal thermocline is a crucial difference between the 2 months (Fig. 8b).

As shown in Fig. 14a, the SWC during April decelerates with increasing distance from the Soya Strait and finally dampens to approximately $0.2 \mathrm{~m} \mathrm{~s}^{-1}$. Throughout the damping, the downslope bottom flow remains everywhere off the coast of the northeastern Hokkaido (Fig. 14b). As a result, the SWC of April is broad and weak in the downstream region, with the offshore cross-isobath velocity $\left(\approx 0.1 \mathrm{~m} \mathrm{~s}^{-1}\right)$ in the whole SWC's flow section (Fig. 15). Such frictional spindown does not occur during August when the seasonal
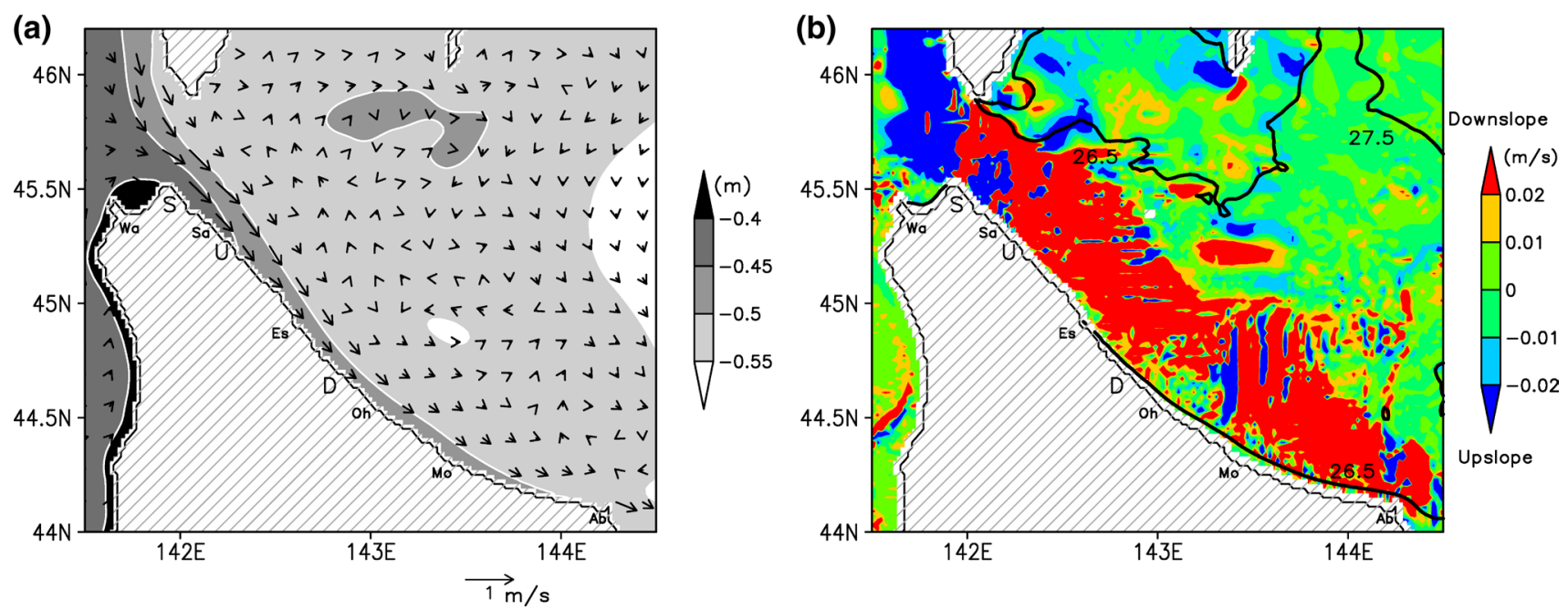

Fig. 14 Same as a Fig. 5a and b Fig. 9, but for April, superimposing the current velocity (arrows) in a 


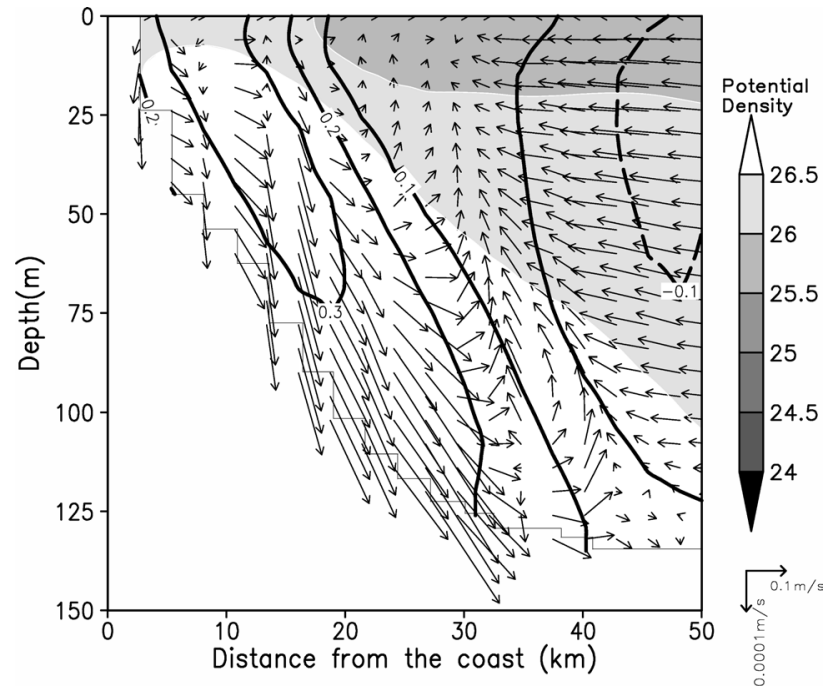

Fig. 15 The same as Fig. 11b, but for April

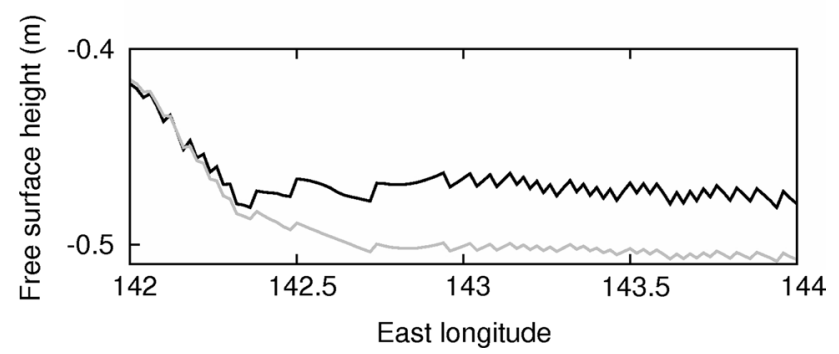

Fig. 16 Monthly mean of simulated sea surface height (SSH) along the isopycnal line of $25.5 \sigma_{\theta}$ in Fig. 9 during August (black line) and April (gray line)

thermocline exists (Figs. 5b, 9, 11b). Thus, the seasonal thermocline-i.e., the buoyancy shutdown process-is essential to make the SWC the strong and narrow coastal current by suppressing the frictional spindown.

The difference between the 2 months is also obvious in the variation of SSH along the line corresponding to the isopycnal of $25.5 \sigma_{\theta}$ near the bottom (Fig. 9). Figure 16 shows that the $\mathrm{SSH}$ decreases up to $142.5^{\circ} \mathrm{E}$ in both months. However, the decrease in $\mathrm{SSH}$ ceases near $142.5^{\circ} \mathrm{E}$ during August, whereas that of April continues further downstream. In other words, the adjustment scale with respect to the buoyancy shutdown $\left(T_{\mathrm{B}}\right)$ becomes shorter than the frictional spindown scale $\left(T_{\mathrm{F}}\right)$. These results can be judged quantitatively by the ratio of the adjustment scales introduced by Chapman 2002, that is,

$T_{\mathrm{F}} / T_{\mathrm{B}}=(N \alpha / f)^{3} N h / u_{0}$,

where $h$ is the water depth; $u_{0}$ is the initial along-isobath velocity. If $T_{\mathrm{F}} / T_{\mathrm{B}} \geq 1(\ll 1)$ Eq. (2), the buoyancy shutdown (the frictional spindown) dominates between the two processes. Since $T_{\mathrm{F}} / T_{\mathrm{B}}=2(=0.125)$ in August (April) by applying $h=100 \mathrm{~m}, u_{0}=1 \mathrm{~m} \mathrm{~s}^{-1}, f=0.0001 \mathrm{~s}^{-1}, \alpha=0.005$, $N=0.02 \mathrm{~s}^{-1}\left(N=0.01 \mathrm{~s}^{-1}\right.$ from Fig. 15), Eq. (2) indicates that the buoyancy shutdown (the frictional spindown) becomes the dominant process during August (April). This is consistent with Fig. 16. Further, the necessary condition for the buoyancy shutdown $\left(T_{\mathrm{F}} / T_{\mathrm{B}} \geq 1\right)$ is also satisfied in the SWC region in July and September, when the seasonal thermocline is enhanced (Fig. 8b). Thus, we conclude that the seasonal thermocline from June to September (see Figs. 3, 6, 8b) is sufficiently strong to keep the SWC vigorous further downstream because the buoyancy shutdown suppresses the frictional spindown.

\section{Summary and discussion}

We studied key processes that create the baroclinic jet structure of the summer SWC with a realistic numerical ocean model (Kuroda et al. 2014). We found that a key process is the buoyancy shutdown process that occurs owing to the interaction between the seasonal thermocline and the bottom Ekman layer on the coastal slope off northeastern Hokkaido; the bottom Ekman transport causes the subduction of warm seasonal thermocline water below the cold lower-layer water, thereby causing development of the bottom mixed layer and tilting the seasonal thermocline vertically. The formation of the baroclinic jet of the summer SWC is associated with the tilting seasonal thermocline in the bottom mixed layer. Finally, offshore buoyancy advection by the bottom Ekman transport vanishes as a result of the thermal wind balance in the mixed layer; hence, the jet development ceases. The bottom mixed layer development, and hence the baroclinic jet development, occurs in the upstream region of the SWC, whereas the baroclinic jet structure is fully developed in the downstream region where the buoyancy shutdown occurs. The buoyancy shutdown theory assesses the SWC mixedlayer thickness to be $50 \mathrm{~m}$, consistent with both the observed (Fig. 2) and numerical (e.g., Fig. 7b) results. The seasonal thermocline from June to September is strong enough to establish the dominance of the buoyancy shutdown process over the frictional spindown.

We noted that the baroclinic jet does not form along the boundary between the salty SWC water and the relatively fresh water originating in the Sea of Okhotsk, because the water mass boundary is not a density front. Further, since the SWC structure is essentially barotropic if bottom friction is absent, the upwelling near the Soya Strait does not cause the formation of the baroclinic jet structure of the SWC far downstream from the strait but the buoyancy shutdown does.

As shown in the numerical (Figs. 7b, 8b, 11b) and observed (Aota 1975; Matsuyama et al. 2006; Fukamachi 
et al. 2008) results, the SWC is not at rest near the bottom, but substantial bottom flows are maintained even in the downstream region. Hence, the conventional theory (e.g., Chapman 2002) is not directly applicable to the SWC in this respect. Since the along-isobath SSH gradient almost vanishes eastward from $142.5^{\circ} \mathrm{E}$ (Fig. 16), the surface pressure gradient cannot account for the bottom flow formation. One of possible effects that produces bottom flows may be the form stress on density interfaces associated with baroclinic instability (Vallis 2006), which transfers upper-layer momentum down to the bottom. Indeed, the contour line of $\sigma_{\theta}=0.1$ in Fig. 10 indicates that the bottom mixed layer is restratified at approximately $143^{\circ} \mathrm{E}$ where the mixing strength is minimal, suggesting the occurrence of baroclinic instability. It is intriguing that mixing is then revitalized farther downstream around $143.5^{\circ} \mathrm{E}$. This may be attributed to the bottom flow interacting with the topographic ridge around $143.5^{\circ} \mathrm{E}$ (Fig. 1b). The formation of bottom flows is thus important for the SWC dynamics and needs further study.

In previous studies, the sea level difference between Wakkanai and Abashiri (e.g., Aota 1975; Shimada et al. 2012) predicts the SWC flow. However, SSH along the baroclinic jet axis away from the Soya Strait is almost uniform in the along-isobath direction (Fig. 16). This implies that the SWC speed in the downstream region does not depend on the along-isobath pressure gradient. Further, Ohshima et al. (2017) showed that the conventional relation exhibits a low correlation coefficient between spring and late autumn and suggested that different mechanisms from the alongshore pressure gradient exist during the period. This may be related to the buoyancy shutdown process discussed in our study.

The simulated turbulent kinetic energy field (Fig. 10) is consistent with the turbulence measurement of Ishizu et al. (2013). The latter showed that the observed vertical mixing was stronger in the upstream area of the SWC (between off Sarufutu and Esashi in Fig. 1b) than that in the downstream (off Ohmu in Fig. 1b). However, the dissipation of the observed temperature variances was not large enough to identify the density inversion. If turbulence measurements and bottom-boundary-layer measurements are carried out in longitudinal section between the Soya Strait and Sarufutu during summer, we expect that stronger vertical mixing caused by offshore buoyancy transport and the downstream evolution of the bottom mixed layer would be observed. This could give us an opportunity to obtain better understanding of the mechanism of the SWC.

Acknowledgements We acknowledge Dr. S. Kida (Kyushu University) and Dr. S. J. Lentz (Woods Hole Oceanic Institution) for their valuable comments. Thanks are extended to Dr. A. Kubokawa, Dr. G. Mizuta, Dr. Y. Isoda and the membership of the EOAS Seminar at Hokkaido University for helpful discussions. We are indebted to Dr. N. Ebuchi for providing the workshop on the Soya Warm Current at the Institute of Low Temperature Science (ILTS), Hokkaido University. Comments from reviewers and the editor improved this paper greatly. Numerical calculations and analyses were conducted with the Pan-Okhotsk Information System at ILTS Hokkaido University, and the figures were prepared by GrADS and gnuplot. This study was partly supported by KAKENHI (26247076, JP16H01585, 17H01156) and the Fisheries Agency project (Shigen Hendo Yoin Bunseki Chosa), but the study contents do not necessarily reflect the views of the Fisheries Agency.

Open Access This article is distributed under the terms of the Creative Commons Attribution 4.0 International License (http://creativeco mmons.org/licenses/by/4.0/), which permits unrestricted use, distribution, and reproduction in any medium, provided you give appropriate credit to the original author(s) and the source, provide a link to the Creative Commons license, and indicate if changes were made.

\section{References}

Allen JS, Newberger PA, Federiuk J (1995) Upwelling circulation on the Oregon continental shelf. Part I: response to idealized forcing. J Phys Oceanogr 25(8):1843-1866

Aota M (1975) Studies on the Soya Warm Current. Low Temp Sci (Ser A) 33:151-172 (in Japanese with English summary)

Aota M, Ishikawa M, Yamada T (1988) Dynamics of flow in the Soya Strait. Low Temp Sci (Ser A) 47:147-160 (in Japanese with English summary)

Benthuysen J, Thomas LN, Lentz SJ (2015) Rapid generation of upwelling at a shelf break caused by buoyancy shutdown. J Phys Oceanogr 45(1):294-312

Brink KH, Lents SJ (2010) Buoyancy arrest and bottom Ekman transport. Part I: steady flow. J Phys Oceanogr 40(4):621-635

Chapman DC (2002) Deceleration of a finite-width, stratified current over a sloping bottom: frictional spindown or buoyancy shutdown? J Phys Oceanogr 32(1):336-352

Chapman DC, Lentz SJ (1997) Adjustment of stratified flow over a sloping bottom. J Phys Oceanogr 27(2):340-356

Ebuchi N, Fukamachi Y, Ohshima KI, Wakatsuchi M (2009) Subinertial and seasonal variations in the Soya Warm Current revealed by HF ocean radars, coastal tide gauges, and bottom-mounted ADCP. J Oceanogr 65(1):31-43

Fukamachi Y, Tanaka I, Ohshima KI, Ebuchi N, Mizuta G, Yoshida H, Takayanagi S, Wakatsuchi M (2008) Volume transport of the Soya Warm Current revealed by bottom-mounted ADCP and oceanradar measurement. J Oceanogr 64(3):385-392

Fukamachi Y, Ohshima KI, Ebuchi N, Bando T, Ono K, Sano M (2010) Volume transport in the Soya Strait during 2006-2008. J Oceanogr 66(5):685-696

Garrett C, MacCready P, Rhines P (1993) Boundary mixing and arrested Ekman layers: rotating stratified flow near a sloping boundary. Annu Rev Fluid Mech 25(1):291-323

Ishizu M, Kitade Y, Matsuyama M (2006) Formation mechanism of the cold-water belt formed off the Soya Warm Current. J Oceanogr 62(4):457-471

Ishizu M, Kitade Y, Michida Y (2013) Mixing process of the northeast coast of Hokkaido in summer. J Oceanogr 69(1):1-13

Kubokawa A (1991) On the behaviour of outflows with low potential vorticity from a sea strait. Tellus A Dyn Meteorol Oceanogr 43(2):168-176

Kuroda H, Setou T, Aoki K, Takahashi D, Shimizu M, Watanabe T (2013) A numerical study of the Kuroshio-induced circulation in Tosa Bay, off the southern coast of Japan. Cont Shelf Res 53:50-62 
Kuroda H, Takahashi D, Mitsudera H, Azumaya T, Setou T (2014) A preliminary study to understand the transport process for the eggs and larvae of Japanese Pacific walleye pollock Theragra Chalcogramma using particle-tracking experiments based on a high-resolution ocean model. Fish Sci 80(2):127-138

Large WG, Yeager SG (2004) Diurnal to decadal global forcing for ocean and sea-ice models: the data sets and flux climatologies. National Center for Atmospheric Research, Boulder

Lee HJ, Jung KT, Foreman MGG, Chung JY (2000) A three-dimensional mixed finite-difference Galerkin function model for the oceanic circulation in the Yellow Sea and the East China Sea. Cont Shelf Res 20(8):863-895

Matsuyama M, Wadaka M, Abe T, Aota M, Koike Y (2006) Current structure and volume transport of the Soya Warm Current in summer. J Oceanogr 62(2):197-205

Mitsudera H, Uchimoto K, Nakamura T (2011) Rotating stratified barotropic flow over topography: mechanisms of the cold belt formation off the Soya Warm Current along the northeastern coast of Hokkaido. J Phys Oceanogr 41(11):2120-2136

Nakanowatari T, Ohshima KI, Mensah V, Mitani Y, Hattori K, Kobayashi M, Roquet F, Sakurai Y, Mitsudera H, Wakatsuchi M (2017) Hydrographic observations by instrumented marine mammals in the Sea of Okhotsk. Polar Sci 13:56-65

Nakata A, Tanaka I, Yagi H, Watanabe T, Kantakov GA, Samatov AD (1999) Formation of high-density water (over 26.8 sigma-t) near the La Perouse Strait (the Soya Strait). PICES Sci Rep 12:145-147

Ohshima KI (1994) The flow system in the Japan Sea caused by a sea level difference through shallow straits. J Geophys Res 99(C5):9925-9940
Ohshima KI, Simizu D, Ebuchi N, Morishima S, Kashiwase H (2017) Volume, heat, and salt transports through the Soya Strait and their seasonal and interannual variations. J Phys Oceanogr 47(5):999-1019

Pedlosky J (1987) Geophyscal fluids dynamics, 2d edn. Springer, Berlin, $\mathrm{p} 728$

Rhines P (1970) Edge-, bottom-, and Rossby waves in a rotating stratified fluid. Geophys Fluid Dyn 1(3-4):273-302

Sakamoto K, Tsujino H, Nishikawa S, Nakano H, Motoi T (2010) Dynamics of the Coastal Oyashio and its seasonal variation in a high-resolution Western North Pacific Ocean model. J Phys Oceanogr 40(6):1283-1301

Shchepetkin AF, McWilliams JC (2005) The regional oceanic modeling system (ROMS): a split-explicit, free-surface, topographyfollowing-coordinate oceanic model. Ocean Model 9(4):347-404

Shimada H, Sawada M, Tanaka I, Asami H, Fukamachi Y (2012) A method for predicting the occurrence of paralytic shellfish poisoning along the coast of Hokkaido in the Okhotsk Sea in summer. Fish Sci 78(4):865-877

Trowbridge JH, Lentz SJ (1991) Asymmetric behavior of an oceanic boundary layer above a sloping bottom. J Phys Oceanogr 21(8):1171-1185

Vallis GK (2006) Atmospheric and ocean fluid dynamics: fundamentals and large-scale circulation. Cambridge University Press, Cambridge, $\mathrm{p} 745$

Yasuda I, Ito S, Shimizu Y, Ichikawa K, Ueda K, Honma T, Uchiyama M, Watanabe K, Sunou N, Tanaka K, Koizumi K (2000) Cold-core anticyclonic eddies south of the Bussol' Strait in the northwestern subarctic Pacific. J Phys Oceanogr 30(6):1137-1157 